\title{
Histomorphological and Histochemical Studies on Proventriculus in Guinea Fowl (Numida meleagris)
}

Devendra Saran ${ }^{1}$, Balwant Meshram

10.18805/IJAR.B-4130

\begin{abstract}
Background: The proventriculus, component of digestive system of bird secretes hydrochloric acid and pepsinogen which helps the churning of food material that takes place in ventriculus. Pepsinogen produces pepsin and it smashes the peptide bonds of amino acid of food material.

Methods: The twelve proventriculus samples of Guinea fowl birds were fixed in 10\% neutral buffered formalin and Bouin's fluid for histological procedure while chilled acetone and chilled ethanol were used as the fixatives for histochemical studies. The fresh unfixed samples were used on cryostat for studies of succinic dehydrogenase enzyme.

Result: Histomorphologically the proventriculus of Guinea fowl was observed as the typical tubular component with four tunics from inside to outside as tunica mucosa, tunica sub mucosa, tunica muscularis and tunica serosa. The submucosal layer comprised with proventricular submucosal gland (PVSMG) which was encapsulated by elastic fibers. Tunica muscularis was inner longitudinal and outer circular layer, while the tunica serosa was observed with surrounding adipose tissue as the connective tissue constituent to endow the access of nutritional supply in the form of blood vessels. The luminal surface of proventricular submucosal glands has shown the significant activity of glycogen while intercalated, intralobular and interlobular ducts have exhibited the weak activity towards the same. The glandular cell rod of PVSMG, serosal layer and adjoining connective tissue with blood vessels has exhibited very weak activity of alkaline phosphatase. Mucosal folds and lumen of PVSMG has shown the weak activity of acidic phosphatase but the serosal limiting membrane has shown very weak activity. The succinic dehydrogenase activity was seen in the connective tissue septa of submucosal glandular cellular rods and the intense activity was observed at tunica muscularis.
\end{abstract}

Key words: Glandular stomach, Guinea fowl (Numida meleagris), Histomorphology, Histochemistry, Proventriculus.

\section{INTRODUCTION}

Bird's stomach is formed by two elements viz. proventriculus and ventriculus viz. gizzard (Saran et al., 2019). In most of the avian species the rod shaped proventriculus is located between esophagus and the ventriculus. It is a glandular segment of the stomach that store food and initiate process of digestion before propelling into the gizzard. Primarily proventriculus secretes hydrochloric acid and pepsinogen which helps the churning of food material that takes place in ventriculus. Pepsinogen produces pepsin and it smashes the peptide bonds of amino acid of food material (Anonymous, 2020).

Morphology of the glandular stomach of Guinea Fowl (Numida Meleagris) is required to be known when the Mewar, tribal belt of Southern Rajasthan is raising this bird seriously as a table food at house hold level. The present histomorphological and histochemical studies on glandular stomach in Guinea fowl is being undertaken while satisfying the scientific thrust area of the same.

\section{MATERIALS AND METHODS}

The twelve samples of proventriculus of Guinea fowl birds were collected at meat shops located in and around the city limit and carried on ice to the laboratory for further processing after histomorphology and histochemistry. The study was carried out during the period of 2017 to 2018, in the Department of Veterinary Anatomy, College of Veterinary and Animal Science, Navania, Udaipur (RAJUVAS, Bikaner) Rajasthan.
Department of Veterinary Anatomy, College of Veterinary and Animal Science, Navania, (RAJUVAS, Bikaner), Udaipur-313 601, Rajasthan, India

'Department of Veterinary Anatomy, College of Veterinary and Animal Science, Guru Angad Dev Veterinary and Animal Sciences University, Ludhiana-141 004 Punjab, India.

Corresponding Author: Devendra Saran, Department of Veterinary Anatomy, College of Veterinary and Animal Science, Guru Angad Dev Veterinary and Animal Sciences University, Ludhiana-141 004 Punjab, India. Email: devvet16@gmail.com

How to cite this article: Saran, D. and Meshram, B. (2021). Histomorphological and Histochemical Studies on Proventriculus in Guinea Fowl (Numida meleagris). Indian Journal of Animal Research. 55(7): 806-809. DOI: 10.18805/IJAR.B-4130.

Submitted: 02-04-2020 Accepted: 29-10-2020 Online: 29-12-2020

The samples were fixed in $10 \%$ neutral buffered formalin and Bouin's fluid for histological procedure while chilled acetone and chilled ethanol were used as the fixatives for histochemical studies. The fresh unfixed samples were used on cryostat for studies of succinic dehydrogenase enzyme. General histological staining were stained after Hematoxyline and Eosine staining procedure, Weigert's staining method was employed for collagen and elastic tissue fibers, other histochemical as to Acidic phosphatase and Alkaline phosphatase were estimated on paraffin sections as per (Luna, 1960, Bancroft and Cook, 1994 and Singh and 
Sulochana, 1996). The McManus's Periodic Acid Schiff's (PAS) method was employed for estimating glycogen. The succinic dehydrogenase activity was observed in cryostat sections as per (Davenport, 1960).

\section{RESULTS AND DISCUSSION Histomorphological studies}

Proventriculus was observed as the typical tubular component with four tunics from inside to outside as tunica mucosa, tunica sub mucosa, tunica muscularis and tunica serosa. Whereas, proventriculus wall is consisted with only three layers viz. tunica mucosa, tunica muscularis and tunica serosa were observed in Yellow billed grosbeak (Zhu et al., 2013).

The tunica mucosal layer was encompassing by elastic and collagen fibers. The lining epithelium of mucosa was tall columnar epithelium. Its mucosal layer was thrown into plicae, the folds which were encountered in different heights. These plicae provide the structure to lumen of the proventriculus at one side while at another it was connecting to the proprial glandular structure as the areolar connective tissue between mucosal and submucosal layer. The lamina propria had an existence of blood vessels and the collagen fibers (Fig 1) and this is similar to the findings of other studies Common moorhen (Gallinula chloropus) (Jassem et al., 2016).

The submucosal layer was consisting of the submucosal glands, which had several secretory tubules within one submucosal gland encapsulated by elastic fibers. This finding similar to reports in turkey (Beheiry, 2018), whereas (Sayrafi and Aghagolzadeh, 2020) reported these glands in the located within the lamina propria of the mucosa of the proventriculus of common starling (Sturnus vulgaris).

Proventricular submucosal glands observed commensing from abluminal to luminal ends. The stratified epithelium of these glands doesn't shown a layer with more than three numbers of cells. It was also observed that, the luminal size of these glands decreses when the number of glands are increases. Frequently only single proventricular submucosal gland was observed with maximize luminal diameter which was surrounded by numerous secretory tubules. Sometime there were two to three submucosal gland were occupying the complete submucosal layer, at the instance sometime no lumen was there among radiating secretory tubules (Fig 2).

The numerous submucosal glands had outer elastic fibers and the inside collagen fibers, blood vessels. As the



Fig 1: Photomicrograph showing the histological details of Proventriculus. LS- Luminal Surface of Organ, PL- Plicae, EP- Epithelium, MF- Mucosal Folds, BV- Blood Vessel, LP- Lamina Propria and PVSMG- Proventricular Submucosal Gland.

Haematoxylin and Eosin 100X

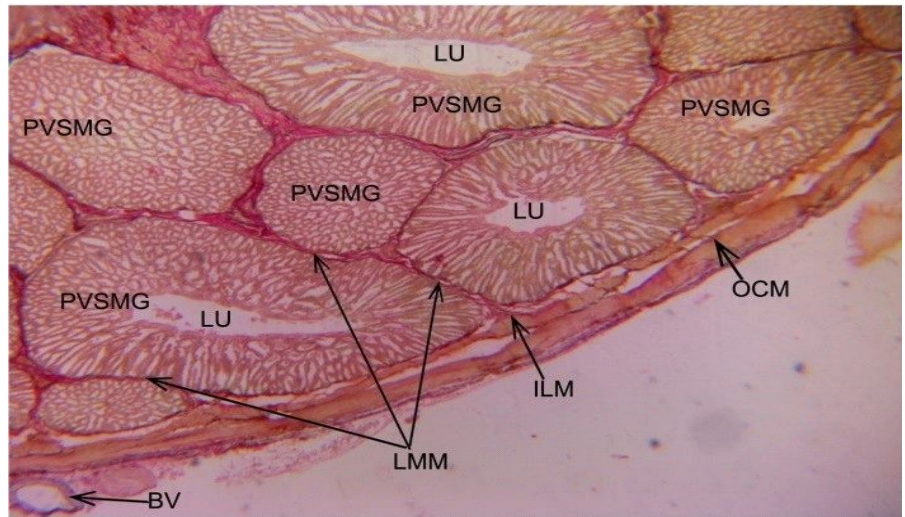

Fig 2: Photomicrograph showing the histological details of Proventriculus. LU- Lumen, PVSMG- Proventricular Submucosal Gland, ILM- Inner Longitudinal Muscle, OCM- Outer Circular Muscle, LMM- Lamina Muscularis Mucosae and BV- Blood Vessel.

Weigert's Stain $40 \mathrm{X}$ 
lobe of submucosal glands it has shown interlobular and intralobular ducts. Even the intralobular duct was also seen.

The parenchyma of each submucosal gland had number of secretory rod in anastomosing way with simple acinar glandular structure which opens into central cavity of these glandular lobules. Simple columnar epithelium was observed at the luminal end.

Tunica muscularis had inner longitudinal and outer thick circular layer, while the tunica serosa was observed with surrounding adipose tissue as the connective tissue constituent to endow the access of nutritional supply in the form of blood vessels. The present findings were completely supporting the observations mentioned by (Das et al., 2017) who has revealed the histomorphological studies on proventriculus in kadaknath fowl but the ducts what they found in the name after primary, secondary and tertiary may be replaced with intercalated, intralobular and interlobular. But the lymphoid infiltration in the lamina propria was not recorded in the present findings.

\section{Histochemical studies}

The mild rose to purplish red i.e. magenta color activity was observed at the luminal surface of submucosal glands. Intercalated, intralobular and interlobular ducts have also exhibited the weak activity towards PAS (Fig 3). These observations were analogous to the results of (Attia, 2008) in quails, (Al-Saffar and Al-Samawy, 2015) in the mallard and (Hamdi et al., 2013) in Black wing kite (Elanus caeruleus) birds. The present findings were encouragingly implied towards the secretion carrying components of proventricular submucosal glands which has higher functional aspect and thereby the proportionate source of energy in the form of carbohydrate macromolecules there.

Intensified weak alkaline phosphatases activity has shown by the glandular cell rods, serosal layer and adjoining connective tissue and the blood vessels in the present studies. Simultaneously a weak acidic phosphatase activity was also noticed in mucosal folds and lumen of proventricular submucosal glands with a very weak activity at serosal limiting membrane. These outcomes were not different than (Selvan et al., 2008) in post hatched Guinea Fowl where they had noticed weak activity in younger and stronger in aged birds. The intensity of activity exhibited in present studies against alkaline and acidic phosphatase might be considered inversely proportional to the functional performance of the activity being shown by those structural components, which were cheering the vigorness of performance being carried out to maintain the uneventful functioning of proventriculus.

Mild SDH activity was observed in connective tissue septa of proventricular submucosal glandular cellular rods while intense in tunica muscularis (Fig 4). However, (Selvan

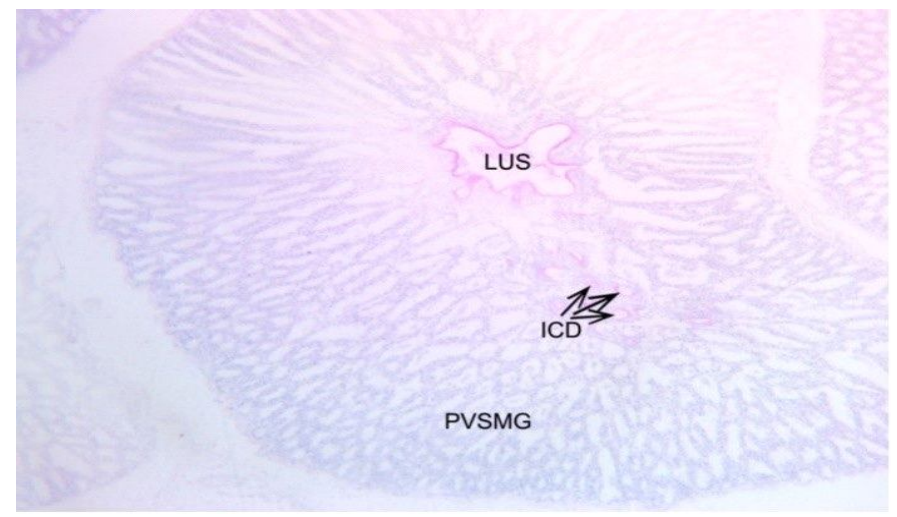

Fig 3: Photomicrograph showing the histological details of Proventriculus. LUS- Luminal Surface, ICD- Intercalated Duct and PVSMG- Proventricular Submucosal Gland.

\section{PAS 100X}



Fig 4: Photomicrograph showing the histological details of Proventriculus. CR- Cellular Rods of Submucosal Glands. Succinic Dehydrogenase 100X 
et al., 2008) had not found any reaction against succinic dehydrogenase in the post hatched Guinea fowl. The present findings were emerging as very promising to the function of proventricular submucosal glands as it has to be involved not only into mitochondrial cell respiration and energy generation but also has to perform for oxygen sensing of the tissue.

\section{CONCLUSION}

Microscopically the proventriculus has shown four tunics, inside to outside, mucosa, submucosa, muscularis and serosa. Mucosal epithelium had tall columnar cells. The plicae were there as the luminal component. Lamina propria shown the blood vessels and collagen fibers. Submucosal glands has shown several secretory tubules and also the intercalated, interlobular and intralobular ducts. The inner longitudinal and outer thick circular layered tunica muscularis was observed. The outermost tunica serosa was observed with its outer adipose tissue. Different histoenzymes were investigated by employing different techniques on paraffin and cryostat sections.

\section{REFERENCES}

Al-Saffar, F.J. and Al-Samawy, E.R.M. (2015). Histomorphological and histochemical Studies of the Stomach of the Mallard (Anas platyrhynchos). Asian Journal of Animal Sciences. 9(6): 280-92.

Anonymous (2020). Proventriculus structure and function. Retrieved from https:// en.wikipedia. org/ wiki/Proventriculus.

Attia, H.F. (2008). Some histological studies on the proventriculus of the quail during pre and post hatching periods. Minufiya Veterinary Journal. 5(2): 441-453.

Bancroft, J.D. and Cook, H.C. (1994). Manual of histological techniques and their diagnostic application. Churchill Livingstone.

Beheiry, R.R. (2018). Histochemical and scanning electron microscopy of proventriculus in Turkey. Journal of Advanced Veterinary and Animal Research. 5(3): 290-298.
Das, S., Dhote, B.S., Singh, GK. and Sinha, S. (2017). Histomorphological and micrometrical studies on the proventriculus of Kadaknath fowl. Journal of Entomology and Zoology Studies. 5(3): 1560-1564.

Davenport, H.A. (1960). Histological and Histochemical Techniques. W.B. Saunders Co., Philadelphia.

Hamdi, H., El-Ghareeb, A.W., Zaher, M. and AbuAmod, F. (2013). Anatomical, histological and histochemical adaptations of the avian alimentary canal to their food habits: II-Elanus caeruleus. International Journal of Scientific and Engineering Research. 4(10): 1355-1364.

Jassem, E.S., Hussein, A.J., and Sawad, A.A. (2016). Anatomical, histological and histochemical study of proventriculus of Common moorhen (Gallinula chloropus). Basrah Journal of veterinary Research. 14(6): 73-82.

Luna, L.G. (1960). Manual of histological staining methods of the Armed forces in institute of pathology. The blackiston division, McGraw -HILL Book Company, Newyork. Co. N.Y. pp. 162, 163 and 164.

Saran, D., Meshram, B., Joshi. H., Singh, G. and Kumar, S. (2019). Gross morphological studies on the digestive system of guinea fowl (Numida meleagris). International Journal of Livestock Research. 9(02): 266-273.

Sayrafi, R. and Aghagolzadeh, M. (2020). Histological and histochemical study of the proventriculus (Ventriculus glandularis) of common starling (Sturnus vulgaris). Anatomia, Histologia, Embryologia. 49(1): 105-111.

Selvan, P.S., Ushakumary, S. and Ramesh, G. (2008). Studies on the histochemistry of the proventriculus and gizzard of post-hatch guinea fowl (Numida meleagris). International Journal of Poultry Science. 7(11): 1112-1116.

Singh, U.B. and Sulochana, S. (1996). Handbook of Histological and Histochemical Techniques, Premier Publishing House, Hyderabad.

Zhu, L., Wang, J.J., Shi, X.D., Hu, J. and Chen, J.G. (2013). Histological observation of the stomach of the yellowbilled grosbeak. International Journal of Morphology. 31(2): 512-515. 